IRA-International Journal of Technology \& Engineering ISSN 2455-4480

Proceedings of the

International Conference on Science \&

Engineering for Sustainable Development (2017)

Pg. no.101-104

Published by: Institute of Research Advances

https://research-advances.org/index.php/IRAJTE

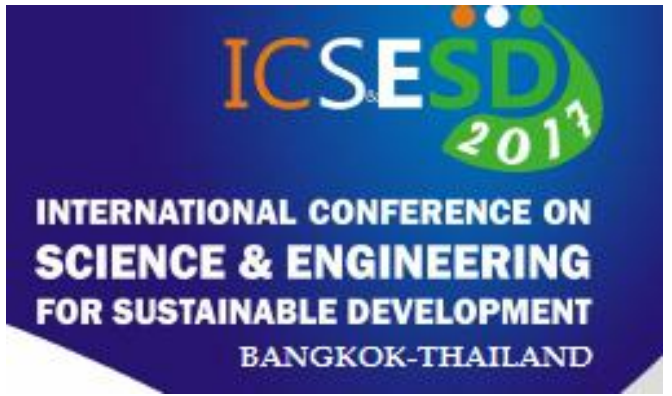

\title{
Multipurpose Low Cost Table Machine
}

\author{
Sanjay S. Shirbhate \\ Lecturer, Shivaji Bahu Uddeshiya Jr. College, Shivaji Nagar, Amravati (M.S.), India. \\ (Email ID :sanjayshirbhate650@gmail.com)
}

Type of Review: Originality Check \& Peer Review under the responsibility of the Scientific Committee of the Conference and The Institution of Engineers (India). DOI: http://dx.doi.org/10.21013/jte.ICSESD201710

\section{How to cite this paper:}

Shirbhate, S. (2017). Multipurpose Low Cost Table Machine. Proceedings of the International Conference on Science \& Engineering for Sustainable Development (2017), 101-104. doi: http://dx.doi.org/10.21013/ite.ICSESD201710

(C) International Conference on Science \& Engineering for Sustainable Development\& The Institution of Engineers (India).

(cc)) BY-NC

This work is licensed under a Creative Commons Attribution-Non Commercial 4.0 International License subject to proper citation to the publication source of the work.

Disclaimer: The conference papers as published by the Institute of Research Advances (IRA) are the views and opinions of their respective authors and are not the views or opinions of the IRA. The IRA disclaims of any harm or loss caused due to the published content to any party. 


\begin{abstract}
The concept of this paper is to develop idea of multipurpose machine as by conducting various operation on same machine, using single operating system. Here, in this machine there is a electric motor which is connected to the pulleys driven by belt (more than one pulley for various speed). The pulley is connected with the shaft which rotate in circular motion and to this shaft circular tools are connected as per required operation as circular saw cuts wooden pieces, pipe cutter will cuts iron rod or iron hollow pipe, grinding circular wheel grinds the job, polishing wheel polishes the job etc. more types of tools and the operation can be done on the same machine. The idea of this machine is to motivate small scale house hold units for ex. Furniture making, office table, Chair, show case for wedding ceremony etc. with low cost machines with multipurpose operation done on same machine.
\end{abstract}

Keywords: Multipurpose Machine, Low cost Machine, Household Machine

\title{
Introduction
}

This multipurpose machine is a working machine and is successfully manufacturing furniture and show items and also won first prize in district level. The concept behind this idea is to combine the various tools operation working on same operating system of a single machine. This machine is very useful for small scale house hold industrial units. This machine can produce furniture from wood, hollow pipes for decoration types of jobs. By this concept I want to appeal to the machine manufacturer such machines for those classes who could not effort to higher costly machine. India is the agriculture base economy country when the crop fail due to natural calamities for the farmer there is no alternative source of live hood. Also the youth from the metros are unemployed with also having good skill with them. This machine will rightly serve the purpose of the farmer and the unemployed youth with the low cost machine which is functioning multipurpose operation. The manufacturer of the machine should look into this matter as instead of selling few costly machine to the some industrialist, we can sell mass low cost machine to the major population in turn will earn huge profit and also fulfill engineer's social responsibility for the mankind. In India Govt. is running "skill India project" under which they are providing finance and also opportunities for the youth for self entrepreneurship.

\section{Working Principle}

Here the as shown in the figure, the shaft is rotated in circular motion by electric motor, to the shaft various circular tools are connected which rotate in circular motion and conduct various operations. 
Parts : As per mentioned in the fig. I, II, III, IV, V. MULTIPURPOSE LOW COST MACHINE

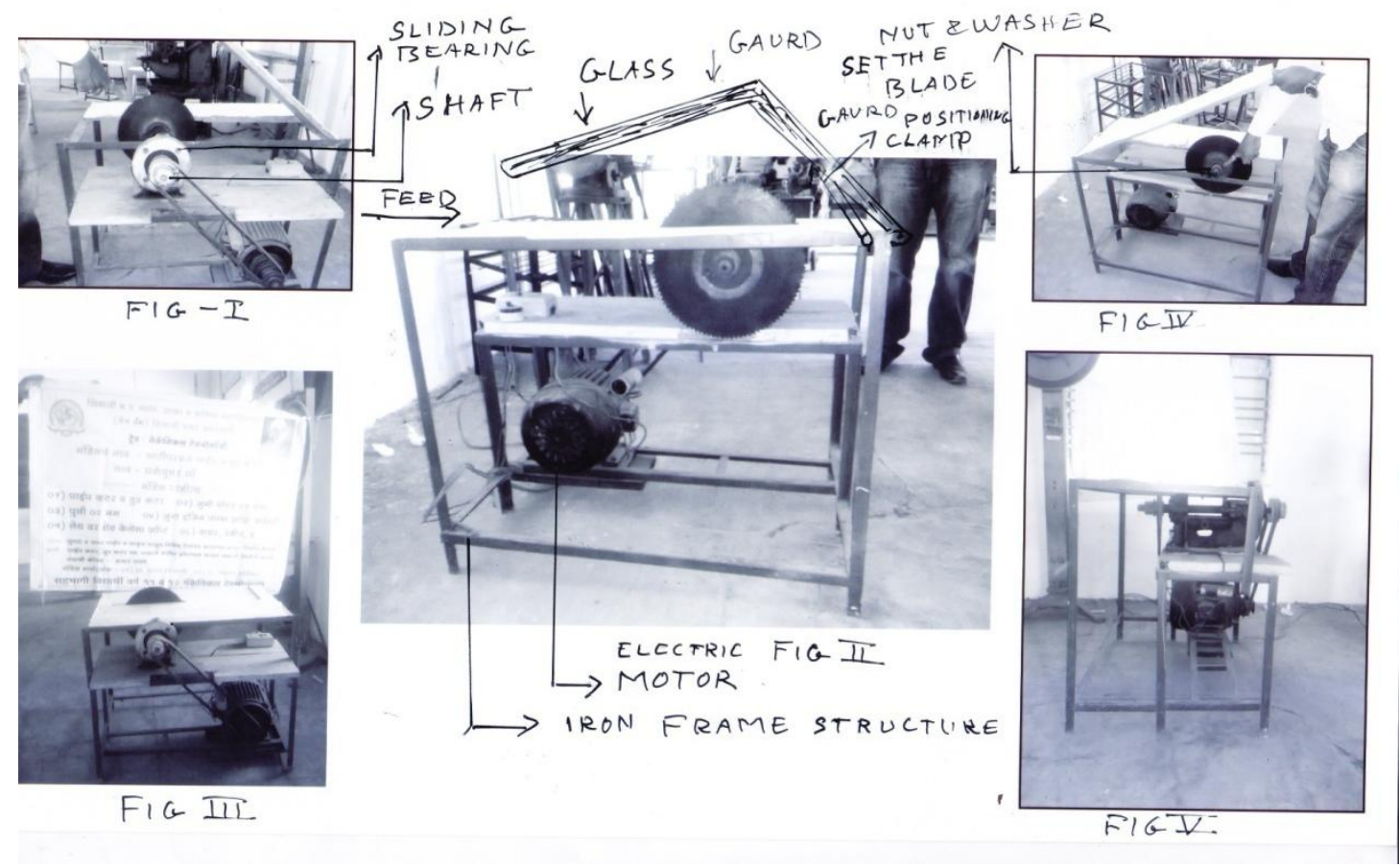

\section{Working}

As shown in fig. I, II, III, IV and V we can vary well see simple design of the machine where there is a iron frame structure on which the electric motor is set on the iron platform which is connected to the step pulley of the shaft through belt. Here the shaft is in the sliding bearing case and to the shaft with the help of washer and nut the various blade are connected. As the motor runs the rotating moment through belt is conveyed to shaft and shaft rotates in the circular motions and conducts the operation. The electric motor can be selected of various horse power as per the work load. The pulley is on the shaft are step pulley and which gives speed variation. The job is feeded as per shown in the fig. from left side. There is a moveable guard with glass which protects the worker from the flames coming from while job cutting. The circular blade of saw cuts the wooden species, the pipe circular cutter cuts the hollow pipe and also cuts iron pieces as per the needs, grinding wheel grind the job, and polishing wheel polishes the job. In this way various operation can be conducted on the same machine. The circular tool can be change just by removing the nut and the washer and replacing the next circular and again tighting the washer and the nut.

\section{Economic Analysis :}

The machine is very low cost as the basic frames structure is of iron costing 1000/- Rs. The electric motor of 2 Horse Power costing 2000/- Rs., sliding bearing and the shaft costing 1500/- Rs. , belt 100/- Rs., various circular blade costing from 800 to 2000/- Rs. each. Total machine is costing approximately $8700 /-$ Rs. which is in the world market approximately of 125 Dollars. 


\section{Summery \& Conclusion / Result}

It is practically successful working machine we have produced thousand of Chairs and furniture for various institute. The profit gain was distribute among the student of the colleges which make the work successful. In the figure $6 \& 7$ also shows the combination work done on a single machine as the fig. 6 shows the sugar cane juice extracting machine where in on the same machine to juice extraction node can be designed. Secondly fig. 7 shows the machine which can grind the wheat floor as well grass cutting and also grain separating combination can be done on the same operating system.
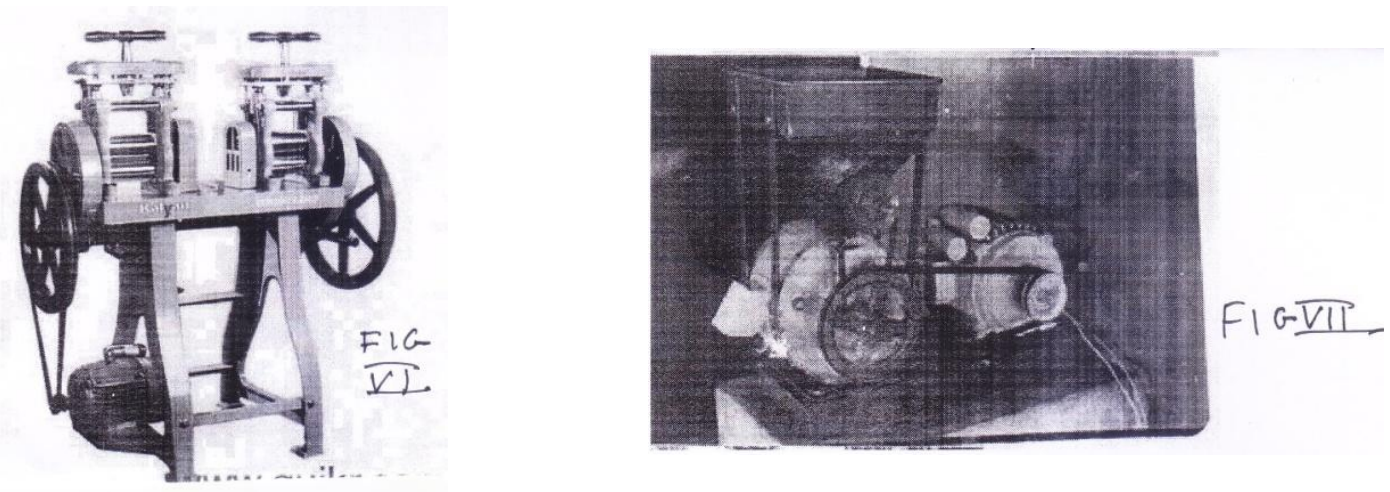

\section{References}

1) Simmy Grewal, Manufacturing process design.

2) Prakash Hiralal Joshi, Machine tool handbook design and operation.

3) V.B. Bhandari, Design of machine element

4) Machine tool operation handbook design publisher McGraw Hill Education (India).

5) www.brighttub9935

Dr. Sanjay S. Shirbhate B.E. (Production), M.B.A., Ph.D. (Marketing) is lecturer in Shivaji Education Society Amravati, working in Mechanical Technology Dept. at Jr. College level. He was the Senate member on S.N.D.T. Womens University Mumbai in 2008, he was chairman of Govt. Sanjay Gandhi Nairadhar Yojana Samiti Amravati (2001-2007), Chairman of Education Committee Amravati Corporation Amravati, State Govt. Award for Sarva Shiksha Abhiyan 2008, Member of Bhrashtachar Nirmulan Amravati Taluka Govt. Committee, paper published in international Journal 2011 July. 